\title{
Factors Associated with Diabetes-Related Clinical Inertia in a Managed Care Population and Its Effect on Hemoglobin A1c Goal Attainment: A Claims-Based Analysis
}

\author{
Natalia Ruiz-Negrón, PharmD; Curtis Wander, PharmD; Carrie McAdam-Marx, RPh, MS, PhD; \\ Jacqueline Pesa, MSEd, PhD, MPH; Robert A. Bailey, MD; and Brandon K. Bellows, PharmD, MS
}

\begin{abstract}
BACKGROUND: Despite evidence showing the benefits of treatment intensification following an elevated hemoglobin A1c (A1c), clinical inertia, or failure to establish and/or escalate treatment to achieve treatment goals, is a concern among patients diagnosed with type 2 diabetes (T2DM). Clinical inertia may contribute to increased health care utilization and costs due to poor clinical outcomes in MCOs.
\end{abstract}

OBJECTIVES: To (a) identify factors associated with clinical inertia in T2DM and (b) determine differences in A1c goal attainment between patients who experience clinical inertia versus treatment intensification in a commercially insured population.

METHODS: Medical and pharmacy claims data were used to identify commercially insured patients in a regional MCO with a recorded A1C $\geq 8.0 \%$ between January 1, 2013, and December 31, 2015. In the 4 months following the first elevated A1c value (index date), patients were classified into 2 groups: treatment intensification or clinical inertia. Treatment intensification was defined as the addition of $\geq 1$ new noninsulin antihyperglycemic medication, the addition of insulin, or a dose increase of any current noninsulin antihyperglycemic medication. Patients were required to have $\geq 1$ follow-up A1c value 6-12 months after the index date and continuous enrollment in the health plan for 12 months before and after the index date. Patients were excluded if they had a diagnosis for gestational diabetes or type 1 diabetes or if they were on insulin in the pre-index period. The primary outcome of attaining A1c $<7.0 \%$ was compared between groups after propensity score matching (PSM). Factors associated with clinical inertia were identified using logistic regression.

RESULTS: 3,078 patients, with a mean (SD) age of 54.4 (10.6) years and a mean (SD) baseline A1c of $9.6 \%$ (1.7), were included in the study. Of these, 1,093 patients (36\%) experienced clinical inertia. After PSM, 1,760 patients remained; 880 in each group. In the clinical inertia group, $23 \%$ of patients achieved an $\mathrm{A} 1 \mathrm{C}<7.0 \%$ in the post-index period, compared with $35 \%$ in the treatment intensification group $(P<0.001)$. A greater likelihood of experiencing clinical inertia was associated with baseline treatment with $2(0 \mathrm{R}=1.51,95 \% \mathrm{Cl}=1.22-2.86 ; P<0.001)$ or $\geq 3(\mathrm{OR}=1.78,95 \% \mathrm{Cl}=1.30$ 2.42; $P<0.001)$ antihyperglycemic medications (vs. none), baseline age $\geq 65$ years $(0 \mathrm{R}=2.11,95 \% \mathrm{Cl}=1.63-2.74 ; P<0.001)$, and diagnosis of coronary heart disease $(\mathrm{OR}=1.44,95 \% \mathrm{Cl}=1.10-1.88 ; P=0.007)$. A baseline A1c $\geq 9.0 \%$ (vs. 8.0\%-8.9\%) was associated with a lower likelihood of experiencing clinical inertia $(\mathrm{OR}=0.56,95 \% \mathrm{Cl}=0.48-0.66 ; P<0.001)$.

CONCLUSIONS: More than a third of patients in a commercially insured population with $\mathrm{T} 2 \mathrm{DM}$ and a baseline $\mathrm{A} 1 \mathrm{C} \geq 8 \%$ experienced clinical inertia. Clinical inertia resulted in worse A1c outcomes over the 12-month follow-up period. Results of this study suggest that treatment intensification should be monitored, with efforts made to educate health care providers on strategies aimed at improving glycemic control for high-risk patients.

J Manag Care Spec Pharm. 2019;25(3):304-13

Copyright $\odot 2019$, Academy of Managed Care Pharmacy. All rights reserved.

\section{What is already known about this subject}

Early and intensive treatment of type 2 diabetes mellitus (T2DM) can lead to the attainment of recommended evidence-based goals of glucose control, as measured by hemoglobin Alc (Alc), which can subsequently reduce diabetes-related complications.

Clinical inertia, or failure to establish treatment goals and/or intensify treatment after a lack of Alc response or loss of Alc control, is a concern.

MCOs are faced with large T2DM populations, so clinical inertia may have a pronounced contribution to increases in health care utilization and costs due to poor clinical outcomes.

\section{What this study adds}

Among commercially insured T2DM patients with an Alc $\geq 8.0 \%$ in a regional MCO, 36\% experienced clinical inertia, which led to a significantly lower proportion of patients attaining an Alc $<7.0 \%$.

Patients using multiple antihyperglycemic medications at the time of an elevated Alc, patients aged $\geq 65$ years, and patients with an Alc between $8.0 \%$ and $9.0 \%$ were more likely to experience clinical inertia

This study adds to the growing body of evidence highlighting the need to decrease the incidence of clinical inertia in patients with T2DM and target those at risk based on patient characteristics.

I $\mathrm{n}$ the United States, an estimated 21.9 million adults are diagnosed with type 2 diabetes mellitus (T2DM). ${ }^{1}$ The annual cost of diabetes in the United States is $\$ 327$ billion, including $\$ 237$ billion in direct medical costs and $\$ 90$ billion in lost productivity. Suboptimal or poor glycemic control is manifested by elevations in hemoglobin Alc (Alc), an indicator of the average blood glucose over the previous 3 months, and increases the risk of cardiovascular disease, microvascular complications, and mortality.,4 To reduce the risk of diabetes-related complications and poor outcomes, the American Diabetes Association (ADA) recommends an Alc treatment goal $<7.0 \%$ for most patients with T2DM. ${ }^{5}$ However, health plan quality measures may have different T2DM treatment control definitions, such as an $\mathrm{Alc}<8.0 \%$ used by 


\section{FIGURE 1 Patient Identification Flowchart}

Adult patients ( $\geq 18$ years) with a diagnosis of T2DM and an $\mathrm{A} 1 \mathrm{C} \geq 8 \%$ (first defines index date) between January 1, 2013, and December 31, 2015 $\mathrm{N}=17,836$

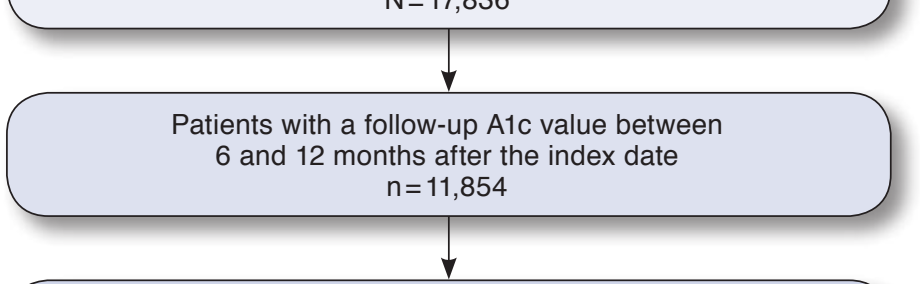

Patients with continuous enrollment in the health plan for $\geq 12$ months before and after the index date $n=5,926$

$\sqrt{2}$

Patients with no history of gestational diabetes or type 1 diabetes and with no pregnancy-related claims during the study period $n=3,832$

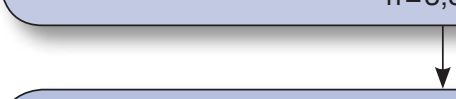

Patients with no pharmacy claims for insulin during the pre-index period

Overall study cohort $\mathrm{N}=3,078$

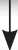

Propensity score matched cohort, $n=1,760$ Clinical inertia, $\mathbf{n}=\mathbf{8 8 0}$

Treatment intensification, $\mathrm{n}=\mathbf{8 8 0}$

Alc=hemoglobin Alc; T2DM = type 2 diabetes mellitus.

the Healthcare Effectiveness Data and Information Set (HEDIS) measures. ${ }^{6}$

Despite the clinical benefits associated with early treatment intensification, clinical inertia-defined by the Agency for Healthcare Research and Quality as failure to intensify therapy within 4 months of an uncontrolled Alc-is common. ${ }^{7-17}$ The prevalence of clinical inertia in patients with T2DM in the United States ranges from $28 \%$ to $73 \%$ and has been associated with older age and lower, yet still above-goal, baseline Alc. ${ }^{11-17}$ However, clinical inertia is multifactorial and may be driven by physician, patient, and system-related factors. ${ }^{10}$ Thus, to design strategies that can successfully target and address this problem, managed care organizations (MCOs) should understand factors associated with clinical inertia in managed care patient populations.

The primary objective of our study was to evaluate the effect of clinical inertia on the attainment of an Alc $<7.0 \%$. To accomplish this, we identified the extent of clinical inertia in a commercially insured patient population and assessed its effect on Alc values in a 6-to 12-month follow-up period. We also aimed to identify factors associated with clinical inertia in our commercial claims data. Our main purpose was to provide MCOs with valuable information that may help identify, prevent, and address this challenge.

\section{Methods}

\section{Study Design}

We conducted a retrospective cohort study that used medical and pharmacy claims data, as well as laboratory data, between January 1, 2012, and September 30, 2016, from commercially insured SelectHealth patients (Figure 1). SelectHealth is a nonprofit regional MCO that covers approximately 850,000 lives from the Intermountain region of the United States with commercial, Medicare, and Medicaid plans available. ${ }^{18}$ The index date was defined as the date of the patient's first $A l c \geq 8.0 \%$ between January 1, 2013, and September 30, 2015. Because patients with an uncontrolled Alc closer to $7.0 \%$ may receive nonpharmacologic recommendations (e.g., diet and exercise), we used an $A l c \geq 8.0 \%$, which aligns with HEDIS health plan quality measures and where pharmacologic intensification is likely to be the most appropriate intervention, to identify patients at risk for experiencing clinical inertia. ${ }^{6,19}$ Patients were required to have at least 1 follow-up Alc value between 6 and 12 months after the index date. The study exposure, treatment intensification versus clinical inertia, was assessed during the 4 -month post-index window (index date -7 days to +120 days). ${ }^{10}$

\section{Patient Population}

In addition to an $A l c \geq 8.0 \%$, patients were required to have at least 1 medical diagnosis of T2DM (identified by International Classification of Diseases, Ninth Revision, Clinical Modification [ICD-9-CM] codes 250.x0 and 250.x2) to be included in the study. Patients were also required to have continuous enrollment (i.e., no gaps in coverage $\geq 90$ days) in their commercial health plan for at least 12 months before and after the index date.

Patients were excluded if they met any of the following criteria: (a) female patients could not have a diagnosis of gestational diabetes or any pregnancy-related claims during the study period (Appendix A, available in online article); (b) patients could not have any insulin prescription claims in the pre-index period, as assessing insulin dose intensification is not reliable using claims data and may have resulted in misclassification of clinical inertia (Appendix B, available in online article) ${ }^{20}$; and (c) patients could not have a medical diagnosis of type 1 diabetes (Appendix A).

\section{Study Variables}

Primary Independent Variable-Clinical Inertia. Clinical inertia was defined as no evidence of T2DM treatment 


\section{Factors Associated with Diabetes-Related Clinical Inertia in a Managed Care Population and Its Effect on Hemoglobin A1c Goal Attainment: A Claims-Based Analysis}

intensification during the 4-month window following an Alc $\geq 8.0 \%{ }^{5,10}$ Treatment intensification was defined as the presence of at least 1 of the following ADA guideline-recommended interventions: (a) a prescription claim for at least 1 new noninsulin antihyperglycemic medication class, (b) a prescription claim for insulin, or (c) an increase in the average daily dose of a current noninsulin antihyperglycemic medication. The average daily dose (i.e., [medication strength (e.g., milligrams) × quantity]/day supply) was calculated from the prescription claim information for each individual antihyperglycemic agent in the 4 months before and after the index date. The time to treatment intensification was quantified as the days until the first change in patients' antihyperglycemic regimen.

Alc Outcomes. The primary study outcome was the proportion of patients who achieved an Alc $<7.0 \%$ on the last recorded Alc between 6 and 12 months after the index date and was compared between the treatment intensification versus the clinical inertia groups. We also compared the difference in follow-up Alc and the change in Alc from baseline between the treatment intensification and clinical inertia groups. To assess for variability in the follow-up time, we described the time until the last recorded Alc in the 6-to 12-month post-index period.

Baseline Characteristics. Patient baseline demographic and clinical characteristics were obtained using data from the 12-month pre-index period up to and including the index date. These characteristics included age, sex, race, baseline Alc at the index date, presence of key comorbidities (identified using ICD-9-CM codes, Appendix A), and receipt of diabetes counseling or education session visits (identified using Current Procedural Terminology codes, Appendix A).

Any baseline antihyperglycemic medication use, including the number and specific classes used, was assessed using pharmacy claims data from the 4-month period before the index date (Appendix B). The adapted Diabetes Complication Severity Index (aDCSI) was also calculated for each patient to assess disease severity (Appendix A). ${ }^{21,22}$ Physician practice type was identified using the physician listed on the first antihyperglycemic pharmacy claim in the post-index period. However, due to the amount of missing data resulting from this approach, we supplemented it using the physician listed on the last outpatient claim for T2DM immediately before the index date. Physician practice type was classified as primary care, specialty (i.e., cardiologists, endocrinologists, and nephrologists), other, or missing.

Other Covariates. To examine potential difficulties in lowering Alc, we evaluated whether patients switched to or added medications with a higher glucose-lowering potential during the post-index year. ${ }^{23-25}$ Based on previous literature, dipeptidyl peptidase-4 inhibitors and alpha glucosidase inhibitors, were considered to have lower glucose-lowering potential than metformin, sulfonylureas, thiazolidinediones, glucagon-like peptide-1 receptor agonists, and meglitinides, which were considered equivalent. ${ }^{23-25}$ For example, an individual on monotherapy with a dipeptidyl peptidase-4 inhibitor at baseline who added metformin to their regimen was considered to have switched to a higher glucose-lowering potential drug. However, if an individual on metformin switched to or added a sulfonylurea, they were not considered to have switched to a higher glucose-lowering potential drug.

We also examined the potential that antihyperglycemic medication switches were due to medication-related adverse events during the pre-index period by describing the incidence of common T2DM medication side effects in the 30 days before the index date (identified using ICD-9-CM codes, Appendix A). We also captured claims for side effects in the 30 days after the index date to allow for delayed claims processing.

\section{Data Analysis}

Descriptive statistics (e.g., mean, standard deviation [SD], median, interquartile range [IQR], frequency, and percentage) were used to report all covariates, and independent Student's t-tests, Mann-Whitney U tests, or chi-square tests were used to assess differences in covariates between the treatment intensification and the clinical inertia group in the overall cohort.

Propensity score matching was then used to balance differences in covariates between patients experiencing clinical inertia and treatment intensification. The propensity score model was created using the Matchit package in $\mathrm{R}$ version 3.1 (R Foundation for Statistical Computing, Vienna, Austria) and included the covariates previously listed in the Baseline Characteristics section. ${ }^{26,27}$ Matching between the groups was carried out using a 1:1 ratio without replacement and a greedy nearest neighbor approach with calipers. A standardized mean difference (SMD) of $<0.1$ was used to indicate adequate covariate balance between groups. ${ }^{28}$

The primary outcome, attainment of Alc $<7.0 \%$, was assessed in the propensity matched cohort using descriptive statistics and compared using a chi-square test. Index and follow-up Alc, as well as the change in Alc in the 6- to 12-month post-index period, were evaluated using descriptive statistics. Independent or paired Student's t-tests were used to assess differences between the matched groups, as appropriate.

For descriptive purposes, the proportion of patients in the unmatched overall cohort experiencing treatment intensification at any time over the post-index period was shown using a cumulative incidence curve. Finally, a multivariable logistic regression model was used in the unmatched overall cohort to assess the odds of experiencing clinical inertia versus treatment intensification. Based on previous clinical and research experience, we examined potential associations between the following baseline characteristics and clinical inertia: age, sex, race/ethnicity, baseline Alc classification (i.e., $\geq 8.0 \%-<9.0 \%$ 


\section{Factors Associated with Diabetes-Related Clinical Inertia in a Managed Care Population and Its Effect on Hemoglobin A1c Goal Attainment: A Claims-Based Analysis}

\section{TABLE 1 Baseline Characteristics and Select Post-Index Treatment Characteristics}

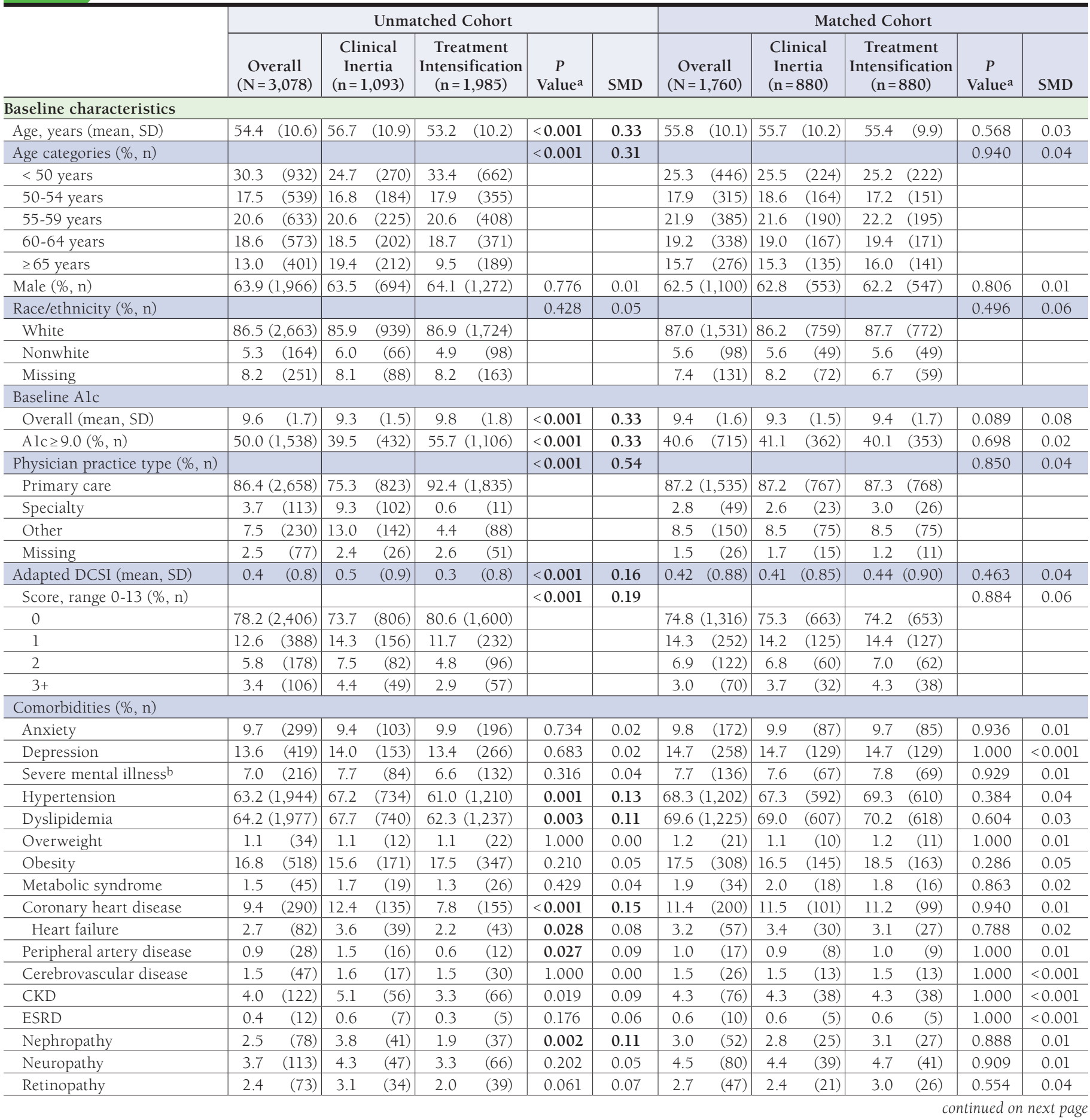

or $\geq 9.0 \%$ ), previous oral antihyperglycemic medication adherence, baseline comorbidities, baseline diabetes counseling/education sessions, and physician practice type. In the final model, we only included covariates with adequate observations and excluded physician practice type due to lack of confidence in the derivation method. We assessed for multicollinearity in the model by evaluating the variance inflation factors associated with each variable. 


\section{Factors Associated with Diabetes-Related Clinical Inertia in a Managed Care Population and Its Effect on Hemoglobin A1c Goal Attainment: A Claims-Based Analysis}

\section{TABLE 1 Baseline Characteristics and Select Post-Index Treatment Characteristics (continued)}

\begin{tabular}{|c|c|c|c|c|c|c|c|c|c|c|}
\hline & \multicolumn{5}{|c|}{ Unmatched Cohort } & \multicolumn{5}{|c|}{ Matched Cohort } \\
\hline & $\begin{array}{c}\text { Overall } \\
(\mathrm{N}=3,078)\end{array}$ & $\begin{array}{l}\text { Clinical } \\
\text { Inertia } \\
(\mathbf{n}=1,093)\end{array}$ & $\begin{array}{c}\text { Treatment } \\
\text { Intensification } \\
(\mathbf{n}=1,985)\end{array}$ & $\begin{array}{c}P \\
\text { Value }^{\mathrm{a}}\end{array}$ & SMD & $\begin{array}{l}\text { Overall } \\
(\mathrm{N}=1,760)\end{array}$ & $\begin{array}{l}\text { Clinical } \\
\text { Inertia } \\
(\mathrm{n}=880)\end{array}$ & $\begin{array}{c}\text { Treatment } \\
\text { Intensification } \\
(\mathbf{n}=880)\end{array}$ & $\begin{array}{c}P \\
\text { Value }^{\mathrm{a}}\end{array}$ & SMD \\
\hline \multicolumn{11}{|l|}{ Treatment characteristics } \\
\hline \multicolumn{11}{|c|}{ Index date antihyperglycemic regimen $(\%, \mathrm{n})$} \\
\hline $\begin{array}{l}\text { Noninsulin } \\
\text { antihyperglycemics } \\
\text { (mean, SD) }\end{array}$ & $0.8 \quad(1.0)$ & (1.1) & $(0.9)$ & $<0.001$ & 0.23 & $0.93 \quad(0.98)$ & $0.92(0.99)$ & $0.95(0.98)$ & 0.561 & 0.03 \\
\hline $\begin{array}{l}\text { Noninsulin } \\
\text { antihyperglycemic } \\
\text { count }(\%, n)\end{array}$ & & & & $<0.001$ & 0.29 & & & & 0.080 & 0.425 \\
\hline 0 & $52.8(1,625)$ & $(537)$ & $54.8(1,088)$ & & & $44.0 \quad(774)$ & $(398)$ & $42.7 \quad(376)$ & & \\
\hline 1 & $24.3 \quad(748)$ & $(222)$ & $26.5 \quad(526)$ & & & $26.1 \quad(460)$ & $(217)$ & $27.6 \quad(243)$ & & \\
\hline 2 & $16.5 \quad(508)$ & $(232)$ & $(276)$ & & & $22.8 \quad(401)$ & $(206)$ & $22.2(195)$ & & \\
\hline$\geq 3$ & $6.4 \quad(197)$ & $(102)$ & $(95)$ & & & $(125)$ & (59) & $7.5 \quad(66)$ & & \\
\hline \multicolumn{11}{|c|}{ Noninsulin antihyperglycemic classes $(\%, \mathrm{n})$} \\
\hline Metformin & $40.1(1,235)$ & $(502)$ & $(733)$ & $<0.001$ & 0.18 & $(878)$ & $(430)$ & $50.9 \quad(448)$ & 0.418 & 0.04 \\
\hline Sulfonylurea & $19.5 \quad(599)$ & $(270)$ & $(329)$ & $<0.001$ & 0.20 & $(412)$ & $(209)$ & $23.1 \quad(203)$ & 0.778 & 0.02 \\
\hline GLP-1 receptor agonists & $4.1 \quad(126)$ & (34) & $(92)$ & 0.052 & 0.08 & $(66)$ & (32) & $3.9 \quad(34)$ & 0.900 & 0.01 \\
\hline TZD & $3.0 \quad(93)$ & $(44)$ & (49) & 0.021 & 0.09 & $(66)$ & $(34)$ & $3.6 \quad(32)$ & 0.900 & 0.01 \\
\hline DPP-4 inhibitor & $9.7 \quad(298)$ & $(142)$ & $(156)$ & $<0.001$ & 0.17 & $11.9 \quad(209)$ & $(100)$ & $12.4(109)$ & 0.556 & 0.03 \\
\hline SGLT2 inhibitors & $0.5 \quad(15)$ & 0.5 & $(10)$ & 1.000 & 0.01 & $0.7 \quad(13)$ & 0.6 & $0.9 \quad(8)$ & 0.578 & 0.04 \\
\hline Alpha-glucosidase inhibitors & 0.1 & 0.1 & 0.1 & 1.000 & 0.00 & 0.0 & 0.0 & 0.0 & - & - \\
\hline Meglitinide & $0.1 \quad(4)$ & 0.0 & 0.2 & 0.336 & 0.06 & 0.0 & 0.0 & 0.0 & - & - \\
\hline $\begin{array}{l}\text { Patients on } \geq 1 \text { fixed-dose } \\
\text { combination antihyperglyce- } \\
\text { mic medication }(\%, n)\end{array}$ & $6.3 \quad(193)$ & $(105)$ & (88) & $<0.001$ & 0.20 & $8.1 \quad(143)$ & (71) & $(72)$ & 1.000 & 0.00 \\
\hline $\begin{array}{l}\text { Patients receiving diabetic } \\
\text { counseling }(\%, \mathrm{n})^{\mathrm{c}}\end{array}$ & $6.5 \quad(201)$ & $(71)$ & $(130)$ & 1.000 & 0.00 & $6.8 \quad(119)$ & (57) & $(62)$ & 0.704 & 0.02 \\
\hline \multicolumn{11}{|c|}{ Antihyperglycemic-related adverse events within \pm 30 days of index date $(\%, \mathrm{n})$} \\
\hline Hypoglycemia & $0.1 \quad(4)$ & $0.1 \quad(1)$ & \begin{tabular}{|l|l|}
0.2 & $(3)$ \\
\end{tabular} & 1.000 & - & 0.2 & 0.1 & 0.2 & 1.000 & - \\
\hline Nausea/vomiting & $(56)$ & (17) & (39) & 0.501 & - & $(25)$ & (15) & $(10)$ & 0.420 & - \\
\hline Edema & 0.2 & 0.5 & 0.1 & 0.111 & - & 0.3 & 0.6 & 0.1 & 0.220 & - \\
\hline Urinary tract infections & $\begin{array}{|ll|}3.2 & (98) \\
\end{array}$ & $\begin{array}{|ll|}3.3 & (36) \\
\end{array}$ & $3.1 \quad(62)$ & 0.881 & - & $3.5 \quad(62)$ & $3.6 \quad(32)$ & $3.4 \quad(30)$ & 0.897 & - \\
\hline \multicolumn{11}{|c|}{$\begin{array}{l}\text { ap values for statistical significance were obtained using independent Student's t-tests for continuous variables or Mann-Whitney U or chi-square tests for categorical } \\
\text { variables, as appropriate; bolded P values indicate statistical significance. } \\
\text { bIncludes schizophrenia, bipolar disorder, and substance abuse. } \\
\text { 'Diabetic counseling identified by CPT code from medical claims. } \\
\text { Alc=hemoglobin Alc; aDCSI = adapted Disease Complication Severity Index; CKD=chronic kidney disease; CPT-4=Common Procedural Terminology, } 4 \text { th Edition, } \\
\text { DPP-4=dipeptidyl peptidase-4; ESRD = end-stage renal disease; GLP-1 = glucagon-like peptide-1; SD =standard deviation; SGLT2=sodium-glucose cotransporter-2; } \\
\text { SMD= standardized mean difference; TZD = thiazolidinedione. }\end{array}$} \\
\hline
\end{tabular}

This study was reviewed and approved by the Intermountain Healthcare Institutional Review Board. All analyses were performed using R. ${ }^{27}$

\section{Results}

\section{Baseline Characteristics}

A total of 3,078 patients were included in the overall patient cohort (Figure 1), with a mean (SD) age of 54.4 (10.6) years and a mean (SD) baseline Alc of 9.6\% (1.7; Table 1). Overall, $63.9 \%$ of patients were male; $86.5 \%$ were white; $63.2 \%$ had hypertension; and $64.2 \%$ had dyslipidemia. During the 4-month post-index period, 1,093 (35.5\%) patients experienced clinical inertia, while 1,985 (64.5\%) had treatment intensification (Figure 2). However, 30\% of patients in the clinical inertia group experienced treatment intensification after the initial 4-month exposure classification window (Figure 2). Among all patients who experienced treatment intensification at any time during the follow-up period, the median (IQR) time to treatment intensification was $2(0-26)$ days.

Patients with clinical inertia appeared to be later in the diabetes disease process than patients in the treatment intensification group. Compared with those with treatment intensification, patients with clinical inertia were older (56.7 [SD 10.9] years vs. 53.2 [SD 10.2] years; $P<0.001$ ), had a higher 


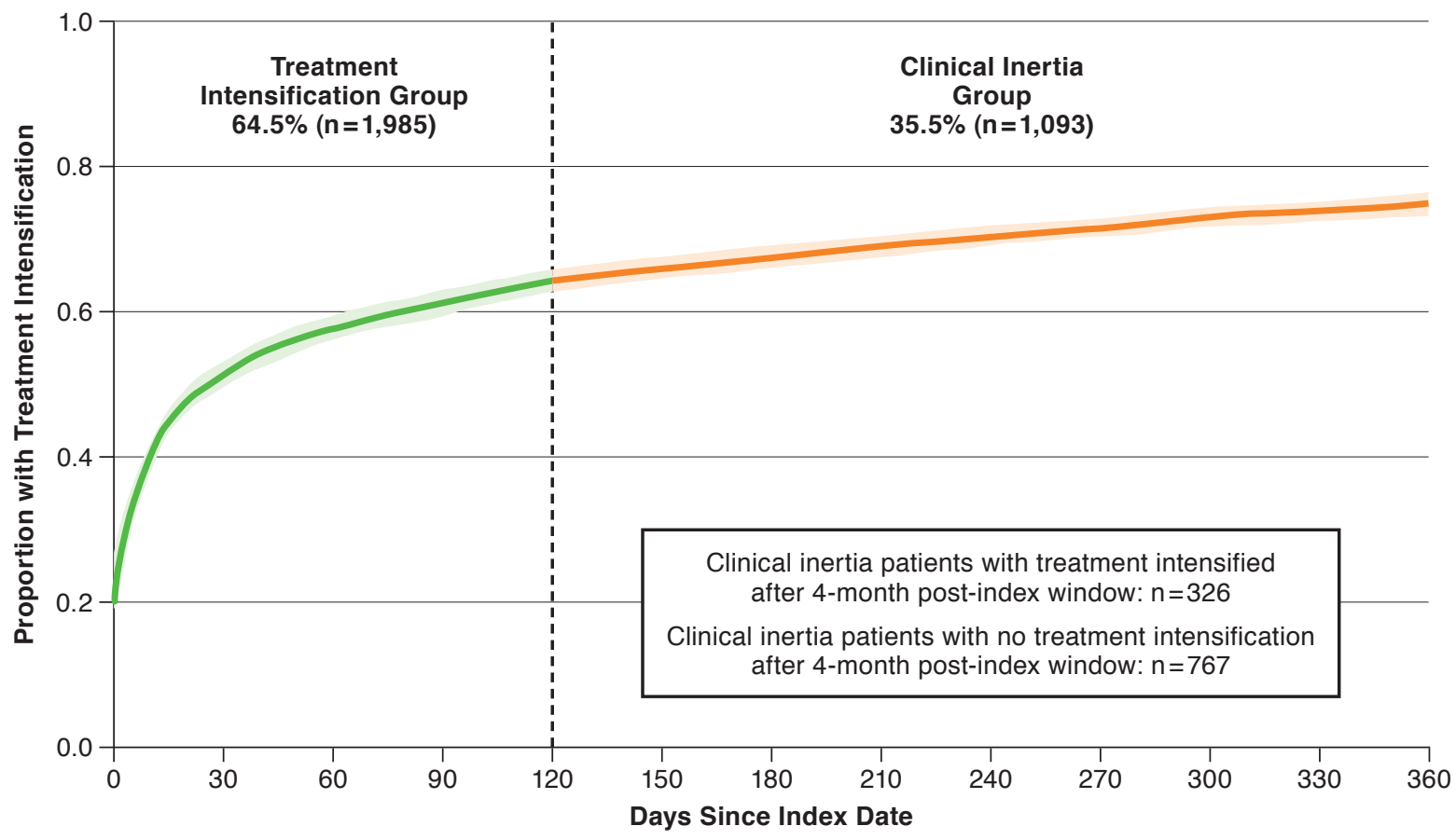

Note: Time to treatment intensification is shown over the post-index year in the overall population. Median time (interquartile range) to treatment intensification was $2(0-26)$ days in the overall cohort; 223 (168-284) days among the clinical inertia patients who had a treatment intensification after 4 months; and 5 (0-22) days among patients in the treatment intensification group.

aDCSI (0.5 [SD 0.9] vs. 0.3 [SD 0.8]; $P<0.001)$, and a greater proportion of them received $\geq 2$ noninsulin antihyperglycemic medications (30.5\% vs. 18.7\%; $P<0.001$ ) at baseline (Table 1 ). Similarly, more patients in the clinical inertia group had a diagnosis of hypertension $(67.2 \%$ vs. $61.0 \% ; P=0.001)$ and dyslipidemia $(67.7 \%$ vs. $62.3 \% ; P=0.003)$ than patients in the treatment intensification group. However, compared with the treatment intensification group, clinical inertia patients had a lower baseline Alc (9.3\% [SD 1.5] vs. 9.8\% [SD 1.8]; $P<0.001$ ).

After propensity score matching, 1,760 patients remained, with 880 patients each in the clinical inertia and treatment intensification groups (Table 1). Similar to the overall cohort, patients in the propensity score matched cohort had a mean (SD) age of 55.8 (10.1) years and a mean (SD) baseline Alc of 9.4\% (1.6). Furthermore, $62.5 \%$ of patients were male; $87.0 \%$ were white; $68.3 \%$ had hypertension; and $69.6 \%$ had dyslipidemia. Covariate balance was achieved, as evidenced by an SMD $<0.1$ for each covariate (Table 1), indicating no statistically significant differences in baseline characteristics between groups after propensity score matching.

\section{Other Covariates}

As expected, more patients in the treatment intensification group switched to or added a medication with a higher glucose-lowering potential in the post-index period than those in the clinical inertia group ( $9.0 \%$ vs. $3.1 \%$; $P=0.001$; data not shown). The incidence of potential medication-related adverse events common in antihyperglycemic medications was low overall (ranged from $0.1 \%$ to $3.2 \%$ ), and no differences were identified between groups (Table 1).

\section{A1c Outcomes}

After propensity score matching, fewer matched patients in the clinical inertia group attained Alc $<7.0 \%$ in the post-index period than in the treatment intensification group (22.6\% vs. $34.4 \%$; $P<0.001$; Table 2). Similarly, despite no statistically significant differences in mean (SD) baseline Alc (clinical inertia 9.3\% [1.5] vs. treatment intensification 9.4\% [1.7]; $P=0.089$ ), matched patients with clinical inertia had a higher mean (SD) follow-up Alc compared with patients with treatment intensification (8.3\% [1.8] vs. $7.8 \%$ [1.8]; $P<0.001$; Table 2). Although both groups had significant reductions in Alc 6-12 months after the index date (paired Student's t-test $P<0.001$ for each group), patients in the treatment intensification group experienced a greater Alc lowering in the 6- to 12-month follow-up period than patients in the clinical inertia group (-1.6\% [SD 2.2] vs. $-1.0 \%$ [SD 2.2]; $P<0.001$; Table 2). Finally, there was no difference in the time to the last Alc value between the groups (Table 2). 
TABLE 2 Unadjusted and Adjusted A1c Outcomes 6-12 Months After Index Date

\begin{tabular}{|c|c|c|c|c|c|c|c|c|}
\hline & \multicolumn{4}{|c|}{ Overall Cohort } & \multicolumn{4}{|c|}{ Matched Cohort } \\
\hline & $\begin{array}{c}\text { Overall } \\
(\mathrm{N}=3,078)\end{array}$ & $\begin{array}{l}\text { Clinical } \\
\text { Inertia } \\
(\mathbf{n}=1,093)\end{array}$ & $\begin{array}{c}\text { Treatment } \\
\text { Intensification } \\
(\mathbf{n}=\mathbf{1 , 9 8 5 )}\end{array}$ & $P$ Value ${ }^{a}$ & $\begin{array}{c}\text { Overall } \\
(\mathrm{N}=1,760)\end{array}$ & $\begin{array}{l}\text { Clinical } \\
\text { Inertia } \\
(\mathrm{n}=880)\end{array}$ & $\begin{array}{c}\text { Treatment } \\
\text { Intensification } \\
(\mathbf{n}=880)\end{array}$ & $P$ Value $^{\mathrm{a}}$ \\
\hline \multicolumn{9}{|l|}{ Primary outcome } \\
\hline \multicolumn{9}{|l|}{ Attainment of Alc goal $(\%, n)$} \\
\hline $\mathrm{Alc}<7.0 \%$ & $31.9 \quad(981)$ & $22.8(249)$ & $36.9(732)$ & $<0.001$ & $28.5(502)$ & $22.6 \quad(199)$ & $34.4(303)$ & $<0.001$ \\
\hline \multicolumn{9}{|c|}{ Other Alc outcomes } \\
\hline \multicolumn{9}{|c|}{ Other follow-up Alc categories $(\%, \mathrm{n})$} \\
\hline Alc $7.0 \%-7.9 \%$ & $26.6 \quad(818)$ & $28.6 \quad(313)$ & $25.4(505)$ & 0.060 & $27.2(478)$ & $26.7 \quad(235)$ & $27.6 \quad(243)$ & 0.708 \\
\hline Alc $8.0 \%-8.9 \%$ & $18.5(570)$ & $21.8(238)$ & $16.7 \quad(332)$ & 0.001 & $19.9(350)$ & $21.6(190)$ & $18.2(160)$ & 0.083 \\
\hline Alc $\geq 9.0 \%$ & $23.0(709)$ & $26.8(293)$ & $21.0 \quad(416)$ & $<0.001$ & $24.4(430)$ & $29.1(256)$ & $19.8 \quad(174)$ & $<0.001$ \\
\hline \multicolumn{9}{|c|}{ Overall Alc measurements (mean, SD) } \\
\hline Baseline Alc & $9.6 \quad(1.7)$ & $9.3 \quad(1.5)$ & $9.8 \quad(1.8)$ & $<0.001$ & $9.4 \quad(1.6)$ & $9.3 \quad(1.5)$ & $9.4 \quad(1.7)$ & 0.089 \\
\hline Follow-up Alc & $8.0 \quad(1.8)$ & $8.2 \quad(1.8)$ & $7.8 \quad(1.8)$ & $<0.001$ & $8.1 \quad(1.8)$ & $8.3 \quad(1.8)$ & $7.8 \quad(1.7)$ & $<0.001$ \\
\hline Change in Alc & $-1.6 \quad(2.4)$ & $-1.1 \quad(2.2)$ & $-2.0 \quad(2.4)$ & $<0.001$ & $-1.3 \quad(2.2)$ & $-1.0 \quad(2.2)$ & $-1.6 \quad(2.2)$ & $<0.001$ \\
\hline $\begin{array}{l}\text { Time of last follow-up Alc, } \\
\text { months (mean [SD]) }\end{array}$ & $8.4 \quad(1.7)$ & $8.4 \quad(1.8)$ & $8.4 \quad(1.7)$ & 0.972 & $8.4 \quad(1.7)$ & $8.4 \quad(1.8)$ & $8.3 \quad(1.7)$ & 0.427 \\
\hline $\begin{array}{l}\text { Last follow-up Alc } \geq 9 \text { months } \\
\text { after index date }(\%, n)\end{array}$ & $35.5(1,093)$ & $35.1 \quad(384)$ & 35.7 (709) & 0.775 & $35.3(621)$ & $35.6 \quad(313)$ & $35.0 \quad(308)$ & 0.842 \\
\hline
\end{tabular}

\section{Factors Associated with Clinical Inertia}

In the overall cohort, several factors were associated with a greater likelihood of experiencing clinical inertia (Table 3). Compared with having no claims for antihyperglycemic medications at baseline, having 2 (odds ratio $[\mathrm{OR}]=1.51,95 \%$ CI [confidence interval] $=1.22-1.86 ; \quad P<0.001)$ or $\geq 3$ antihyperglycemic medications $(\mathrm{OR}=1.78,95 \% \mathrm{CI}=1.30-2.42$; $P<0.001)$ was associated with a higher odds of clinical inertia. Conversely, having a claim for 1 antihyperglycemic medication (vs. none) at baseline was associated with a lower odds of experiencing clinical inertia $(\mathrm{OR}=0.75,95 \% \mathrm{CI}=0.61-0.91$; $P=0.004)$. The presence of a coronary heart disease (OR $=1.44$, $95 \% \mathrm{CI}=1.10-1.88 ; P=0.007)$ was associated with a greater odds of experiencing clinical inertia, as was a baseline age $\geq 65$ years versus age $<50$ years $(\mathrm{OR}=2.11,95 \% \mathrm{CI}=1.63-2.74$; $P<0.001)$. Conversely, having a baseline Alc $\geq 9.0 \%$ was associated with a lower odds of experiencing clinical inertia than having a baseline Alc between $8.0 \%$ and $<9.0 \%(\mathrm{OR}=0.56$, $95 \% \mathrm{CI}=0.48-0.66 ; P<0.001)$. In sensitivity analyses, the results of the regression were minimally affected by inclusion of variables with a small number of observations and physician practice type (data not shown).

\section{Discussion}

In this claims-based analysis, $36 \%$ of commercially insured patients did not have their treatment intensified within 4 months of an $\mathrm{Alc} \geq 8.0 \%$. Of these patients with clinical iner- tia, only $30 \%$ of patients experienced treatment intensification between 4 and 12 months after the index date (i.e., after the window used to define treatment intensification). Compared with the $64 \%$ of patients with treatment intensification, patients with clinical inertia had a higher mean follow-up Alc, and a lower proportion attained an Alc $<7.0 \%$ in the 6-12 months following the elevated Alc. Baseline characteristics associated with an increased likelihood of experiencing clinical inertia included the use of $\geq 2$ antihyperglycemic medications at baseline, a baseline age $\geq 65$ years, and a diagnosis of coronary heart disease. Conversely, characteristics associated with a lower likelihood of experiencing clinical inertia included a baseline Alc $\geq 9.0 \%$ and the use of 1 antihyperglycemic medication at baseline.

Several previous retrospective studies evaluating clinical inertia in the United States have been published. ${ }^{13-17}$ Of these, only the study by Pantalone et al. (2016) had a similar Alc threshold as our study when defining clinical inertia $(\mathrm{Alc}>8.0 \%) .{ }^{16}$ In that study, $28 \%$ of patients experienced clinical inertia at 6 months. ${ }^{16}$ Other studies reported 50\%-73\% of patients experiencing clinical inertia within either a 6 - or 12-month post-index period..$^{13-15}$ However, these studies used different criteria to define patients at risk for clinical inertia (e.g., Alc $\geq 7.0 \%$ ) and also required patients to be on metformin at baseline.$^{13-15}$ Conversely, our study included all patients with an Alc $\geq 8.0 \%$ regardless of their previous oral antihyperglycemic treatment regimen. Patients in our study may have been more likely to experience treatment intensification due to the higher baseline Alc required to determine if an individual was 


\begin{tabular}{|c|c|c|c|}
\hline $\begin{aligned} \text { TABLE } 3 \text { Logistic Regre } \\
\text { of Experiencin } \\
\text { Overall Unmat }\end{aligned}$ & $\begin{array}{l}\text { on Pre } \\
\text { Clinic } \\
\text { hed C }\end{array}$ & $\begin{array}{l}\text { dicting } \mathrm{Od} \\
\text { Inertia in } \\
\text { hort }(\mathrm{N}=3\end{array}$ & $\begin{array}{l}\text { ds } \\
\text { the } \\
\text { 078) }\end{array}$ \\
\hline Variables & $\begin{array}{l}\text { Odds } \\
\text { Ratio }\end{array}$ & $95 \%$ CI & $\begin{array}{c}P \\
\text { Value }^{\mathrm{a}}\end{array}$ \\
\hline $\begin{array}{l}\text { Clinical inertia } \\
\text { (ref: treatment intensification) }\end{array}$ & - & - & - \\
\hline $\begin{array}{l}\text { Baseline age category, years } \\
\text { (ref: }<50 \text { years) }\end{array}$ & - & - & - \\
\hline $50-54$ years & 1.16 & $(0.92-1.47)$ & 0.211 \\
\hline $55-59$ years & 1.20 & $(0.96-1.50)$ & 0.113 \\
\hline $60-64$ years & 1.08 & $(0.86-1.37)$ & 0.511 \\
\hline$\geq 65$ years & 2.11 & $(1.63-2.74)$ & $<0.001$ \\
\hline Male (ref: female) & 1.01 & $(0.86-1.19)$ & 0.902 \\
\hline Race (ref: white) & - & - & - \\
\hline Nonwhite & 1.32 & $(0.94-1.84)$ & 0.105 \\
\hline Missing & 0.99 & $(0.75-1.31)$ & 0.953 \\
\hline $\begin{array}{l}\text { Baseline Alc } \geq 9.0 \% \\
\text { (Ref: Alc } \geq 8.0 \% \text { to }<9.0 \% \text { ) }\end{array}$ & 0.56 & $(0.48-0.66)$ & $<0.001$ \\
\hline $\begin{array}{l}\text { Baseline number of antihyperglycemic } \\
\text { medications (ref: 0) }\end{array}$ & - & - & - \\
\hline 1 & 0.75 & $(0.61-0.91)$ & 0.004 \\
\hline 2 & 1.51 & $(1.22-1.86)$ & $<0.001$ \\
\hline$\geq 3$ & 1.78 & $(1.30-2.42)$ & $<0.001$ \\
\hline Receiving diabetic counseling at baseline & 0.91 & $(0.66-1.24)$ & 0.547 \\
\hline Baseline comorbidities & - & - & - \\
\hline Anxiety & 0.95 & $(0.72-1.26)$ & 0.733 \\
\hline Depression & 1.10 & $(0.86-1.39)$ & 0.451 \\
\hline Severe mental illness & 1.11 & $(0.81-1.50)$ & 0.516 \\
\hline Hypertension & 1.09 & $(0.92-1.30)$ & 0.326 \\
\hline Dyslipidemia & 1.03 & $(0.86-1.22)$ & 0.766 \\
\hline Obesity & 0.81 & $(0.65-1.00)$ & 0.054 \\
\hline Coronary heart disease & 1.44 & $(1.10-1.88)$ & 0.007 \\
\hline Chronic kidney disease & 0.99 & $(0.64-1.51)$ & 0.953 \\
\hline Nephropathy & 1.47 & $(0.87-2.48)$ & 0.150 \\
\hline Neuropathy & 1.00 & $(0.66-1.50)$ & 0.993 \\
\hline Retinopathy & 1.20 & $(0.73-1.96)$ & 0.464 \\
\hline $\begin{array}{l}\text { aP values for statistical significance were obtc } \\
\text { model; bolded } P \text { values indicate statistical sig } \\
\text { Alc=hemoglobin } A 1 c ; C I=\text { confidence interve }\end{array}$ & $\begin{array}{l}\text { d from } \\
\text { cance. } \\
\text { ref }=\text { refe }\end{array}$ & $\begin{array}{l}\text { logistic regres } \\
\text { nce. }\end{array}$ & \\
\hline
\end{tabular}

at risk for clinical inertia. We used this threshold to reduce the risk of misclassifying behaviors not identifiable in claims databases (e.g., diet and exercise) as clinical inertia, since they are more likely to occur when Alc is closer to $7.0 \%{ }^{19}$

Despite differences in inclusion criteria, our study and the other U.S. studies found clinical inertia to be associated with older age and a higher number of baseline antihyperglycemic medications. ${ }^{13-15}$ With increasing age and medication use, patients and providers may have concerns about an increased risk of medication-related adverse events, polypharmacy, and burden of disease management. In patients with complications and shorter life expectancy, such as older adult patients, treatment guidelines, therefore, recommend less aggressive Alc targets (e.g., < $8.0 \%$ vs. < $7.0 \%){ }^{5}$ However, our study used the higher Alc threshold to identify patients at risk for clinical inertia and results indicate that provider and MCO efforts to address clinical inertia in patients $\geq 65$ years and those on $\geq 2$ antihyperglycemic medications would be beneficial and could potentially improve patient outcomes and health plan quality performance measures. Thus, this study contributes to a growing body of evidence that supports targeting patients who are at risk of diabetes-related clinical inertia based on patient characteristics. However, some patient characteristics, such as coronary heart disease and hypertension, have had mixed results in published literature and warrant further examination in future research.

Overall, our results show that the majority of patients with T2DM and an elevated Alc experienced treatment intensification within 4 months. However, many patients are not receiving timely treatment intensification and may be at higher risk for long-term complications. ${ }^{4}$ At the population level, this failure to intensify therapy may also translate to MCOs' lower performance on diabetes-related quality measures (e.g., HEDIS scores). ${ }^{6}$ Because clinical inertia is multifactorial, it is important for health care decision makers to understand the physician, patient, and system factors that may contribute to clinical inertia within their systems and develop interventions to overcome them. As many MCOs have existing T2DM care management teams and processes, patients with characteristics associated with clinical inertia may be targeted and prioritized within these systems. Regardless of the method used, to optimize the management of patients with T2DM, it is important for MCOs and health care decision makers to use information such as that provided in this study to identify patients at risk for clinical inertia and intervene as appropriate.

\section{Limitations}

Our study has several limitations that should be taken into consideration. We excluded patients with insulin use in the pre-index period because insulin dose is not included in claims data and estimations of dose based on quantity dispensed are unreliable (i.e., issues with vial expiration dates, variable or sliding scale insulin dosing, and improper syringe use). ${ }^{20} \mathrm{We}$ intentionally did this to avoid potential misclassification bias in patients with insulin claims. However, this may have limited the number and type of patients considered in the analysis. In addition, this study included a substantial number of patients without prescription claims for antihyperglycemic therapy in the previous year. Thus, our cohort likely included newly diagnosed patients. This approach increased the generalizability of our findings but may have also led to a higher estimate of intensification rates versus other studies, as barriers to initiating first-line therapy were likely lower than adding other agents or insulin. ${ }^{29}$ 


\section{Factors Associated with Diabetes-Related Clinical Inertia in a Managed Care Population and Its Effect on Hemoglobin A1c Goal Attainment: A Claims-Based Analysis}

As with all claims-based analyses, the recommendation of and adherence to nonpharmacologic interventions was not captured in our study. After receiving an Alc lab result $\geq 8.0 \%$, management strategies other than antihyperglycemic medication intensification, such as counseling on lifestyle changes and adherence, may be used by clinicians. Similarly, health plan formulary, a factor that may affect the incidence of clinical inertia, cannot be captured using claims data. These items may represent a source of unmeasured confounding. Additionally, many antihyperglycemic medications are available at a reduced price on pharmacy generic drug lists, which may prompt patients to pay for their medications using cash, which would not have been captured in any claims dataset.

Furthermore, pharmacy claims data provide information on medications that are prescribed by physicians and filled by a pharmacy. Prescriptions that patients failed to fill were not included, thus, these data represented treatment intensification associated with patient follow-through with the physician prescribing recommendations. Similarly, the presence of prescription claims does not guarantee that patients actually took their medication, which may have potentially misclassified some nonadherent patients as having experienced treatment intensification. Although we examined some variables that could identify potential physician motivations surrounding changes in therapy (e.g., common side effects), future analyses should consider the added use of electronic medical record data, which contain prescription orders, laboratory results, and clinical notes, to further account for potential confounders.

In addition, this study was designed to measure the effect on surrogate measures over a 12-month time horizon. Future studies should consider the effect of clinical inertia on longterm health outcomes. Finally, while we used Alc $<7.0 \%$ as the outcome threshold, that level may not be appropriate for all patients with T2DM, especially those with a history of severe hypoglycemia and limited life expectancy. ${ }^{4}$ However, this goal is considered adequate for many patients with T2DM and represents a clinically significant improvement in glycemic control.

\section{Conclusions}

Clinical inertia occurred in over a third of patients with uncontrolled T2DM and was most likely to occur in patients aged $\geq 65$ years, were prescribed $\geq 2$ antihyperglycemic medications, had an Alc 8.0\%-9.0\%, and had coronary heart disease. As expected, patients with clinical inertia had worse follow-up Alc outcomes over the study period, but when treatment was intensified, follow-up Alc was lower than baseline. These data provide compelling evidence for MCOs to promote treatment intensification and target patients at high risk of experiencing clinical inertia. These results may help MCOs create interventions that may help better manage T2DM and reduce health care utilization.

\section{Authors}

NATALIA RUIZ-NEGRÓN, PharmD, Department of Pharmacotherapy, University of Utah, Salt Lake City, and SelectHealth, Murray, Utah. CURTIS WANDER, PharmD, SelectHealth, Murray, Utah; CARRIE MCADAM-MARX, RPh, MS, PhD, Pharmaceutical Evaluation and Policy Division, University of Arkansas for Medical Sciences, Little Rock; and BRANDON K. BELLOWS, PharmD, MS, Division of General Medicine, Columbia University, New York, New York. JACQUELINE PESA, MSEd, PhD, MPH, and ROBERT A. BAILEY, MD, Janssen Scientific Affairs, Titusville, New Jersey.

AUTHOR CORRESPONDENCE: Natalia Ruiz-Negrón, PharmD, Department of Pharmacotherapy, University of Utah, 30 South 2000 East, Rm. 4963, Salt Lake City, UT 84112. Tel.: 801.581.7393; E-mail: natalia.ruiz@pharm.utah.edu.

\section{DISCLOSURES}

This study was funded by a grant from Janssen Scientific Affairs, which was involved in study design, interpretation of results, and manuscript review. Wander reports consulting fees from Sanofi Aventis outside the submitted work. McAdam-Marx reports grants from Sanofi Aventis and AstraZeneca outside the submitted work. Pesa and Bailey were employees of Janssen Scientific Affairs during the conduct of the study. Bailey also reports stock ownership in Johnson and Johnson.

This study was presented as a poster at the Academy of Managed Care Pharmacy Nexus 2017; October 16-19, 2017; Grapevine, TX.

\section{REFERENCES}

1. American Diabetes Association. Statistics about diabetes. 2017. Available at: http://www.diabetes.org/diabetes-basics/statistics/. Accessed December 22, 2018.

2. American Diabetes Association. Economic costs of diabetes in the U.S. in 2017. Diabetes Care. 2018;41(5):917-28

3. Khaw KT, Wareham N, Bingham S, Luben R, Welch A, Day N. Association of hemoglobin Alc with cardiovascular disease and mortality in adults: the European prospective investigation into cancer in Norfolk. Ann Intern Med. 2004;141(6):413-20.

4. UK Prospective Diabetes Study (UKPDS) Group. Effect of intensive bloodglucose control with metformin on complications in overweight patients with type 2 diabetes (UKPDS 34). Lancet. 1998;352(9131):854-65.

5. American Diabetes Association. Standards of medical care in diabetes 2018. Diabetes Care. 2018;41(Suppl 1):S1-S155.

6. National Committee for Quality Assurance. HEDIS measures. 2018. Available at: http://www.ncqa.org/hedis-quality-measurement/hedis-measures. Accessed December 22, 2018.

7. Group AC, Patel A, MacMahon S, et al. Intensive blood glucose control and vascular outcomes in patients with type 2 diabetes. N Engl J Med. 2008;358(24):2560-72

8. van Dieren S, Kengne AP, Chalmers J, et al. Intensification of medication and glycaemic control among patients with type 2 diabetes-the ADVANCE trial. Diabetes Obes Metab. 2014;16(5):426-32.

9. Romanelli RJ, Chung S, Pu J, Nimbal V, Zhao B, Palaniappan L. Comparative effectiveness of early versus delayed metformin in the treatment of type 2 diabetes. Diabetes Res Clin Pract. 2015;108(1):170-78. 


\section{Factors Associated with Diabetes-Related Clinical Inertia in a Managed Care Population and Its Effect on Hemoglobin A1c Goal Attainment: A Claims-Based Analysis}

10. O'Connor PJ, Sperl-Hillen JM, Johnson PE, Rush WA, Blitz, G. Clinical inertia and outpatient medical errors. In: Henriksen K, ed. Advances in patient safety: from research to implementation. Vol. 2: Concepts and methodology. February 2005. Agency for Healthcare Research and Quality. Rockville, MD. Available at: https://www.ncbi.nlm.nih.gov/books/ NBK20513/pdf/Bookshelf_NBK20513.pdf. Accessed December 22, 2018

11. Rajpathak SN, Rajgopalan S, Engel SS. Impact of time to treatment intensification on glycemic goal attainment among patients with type 2 diabetes failing metformin monotherapy. J Diabetes Complications. 2014;28(6):831-35.

12. Davis J, Chavez B, Juarez DT. Adjustments to diabetes medications in response to increases in hemoglobin alc: An epidemiologic study. Ann Pharmacother. 2014:48(1):41-47.

13. Fu AZ, Qiu Y, Davies MJ, Radican L, Engel SS. Treatment intensification in patients with type 2 diabetes who failed metformin monotherapy. Diabetes Obes Metab. 2011;13(8):765-69.

14. Lin J, Zhou S, Wei W, Pan C, Lingohr-Smith M, Levin P. Does clinical inertia vary by personalized Alc goal? A study of predictors and prevalence of clinical inertia in a U.S. managed-care setting. Endocr Pract. 2016;22(2):151-61.

15. Yu S, Schwab P, Bian B, Radican L, Tunceli K. Use of add-on treatment to metformin monotherapy for patients with type 2 diabetes and suboptimal glycemic control: a U.S. database study. J Manag Care Spec Pharm. 2016;22(3):272-80. Available at: https://www.jmcp.org/doi/10.18553/ jmcp. 2016.22.3.272.

16. Pantalone KM, Wells BJ, Chagin KM, et al. Intensification of diabetes therapy and time until AlC goal attainment among patients with newly diagnosed type 2 diabetes who fail metformin monotherapy within a large integrated health system. Diabetes Care. 2016;39(9):1527-34.

17. Zhang Q, Rajagopalan S, Marrett E, Davies MJ, Radican L, Engel SS. Time to treatment initiation with oral antihyperglycaemic therapy in U.S. patients with newly diagnosed type 2 diabetes. Diabetes Obes Metab. 2012;14(2):149-54

18. SelectHealth. About SelectHealth. 2018. Available at: http://selecthealth. org/about/Pages/home.aspx. Accessed December 22, 2018.
19. Marrett E, Zhang Q, Kanitscheider C, Davies MJ, Radican L, Feinglos MN. Physician reasons for nonpharmacologic treatment of hyperglycemia in older patients newly diagnosed with type 2 diabetes mellitus. Diabetes Ther. 2012;3(1):5.

20. Stolpe S, Kroes MA, Webb N, Wisniewski T. A systematic review of insulin adherence measures in patients with diabetes. J Manag Care Spec Pharm. 2016;22(11):1224-46. Available at: https://www.jmcp.org/ doi/10.18553/jmcp.2016.22.11.1224.

21. Chang HY, Weiner JP, Richards TM, Bleich SN, Segal JB. Validating the adapted diabetes complications severity index in claims data. Am J Manag Care. 2012;18(11):721-26.

22. Hazel-Fernandez L, Li Y, Nero D, et al. Relationship of diabetes complications severity to healthcare utilization and costs among Medicare Advantage beneficiaries. Am J Manag Care. 2015;21(1):e62-70.

23. Agency for Healthcare Research and Quality. Diabetes medications for adults with type 2 diabetes: an update. Comparative Effectiveness Review 173 AHRQ Publication No. 16-EHC013-EF. April 2016. Agency for Healthcare Research and Quality. Rockville, MD. Available at: https://www.ncbi.nlm.nih. gov/books/NBK362863/. Accessed December 22, 2018.

24. American Diabetes Association. 8. Pharmacologic approaches to glycemic treatment. Standards of medical care in diabetes. Diabetes Care. 2018;41(Suppl 1):S75-S85.

25. Palmer SC, Mavridis D, Nicolucci A, et al. Comparison of clinical outcomes and adverse events associated with glucose-lowering drugs in patients with type 2 diabetes: a meta-analysis. JAMA. 2016;316(3):313-24.

26. Ho DE, Imai K, King G, Stuart EA. MatchIt: nonparametric preprocessing for parametric pausal pnference. J Stat Software. 2011;42(8):1-28.

27. R Core Team. R: A language and environment for statistical computing. R Foundation for Statistical Computing. Vienna, Austria. 2018. Available at: https://www.gbif.org/tool/81287/r-a-language-and-environment-for-statistical-computing. Accessed January 2, 2019.

28. Harder VS, Stuart EA, Anthony JC. Propensity score techniques and the assessment of measured covariate balance to test causal associations in psychological research. Psychol Methods. 2010;15(3):234-49.

29. Khunti K, Millar-Jones D. Clinical inertia to insulin initiation and intensification in the UK: a focused literature review. Prim Care Diabetes. 2017;11(1):3-12 


\section{Factors Associated with Diabetes-Related Clinical Inertia in a Managed Care Population and Its Effect on Hemoglobin A1c Goal Attainment: A Claims-Based Analysis}

\section{APPENDIX A List of ICD-9/10-CM and CPT Codes}

\begin{tabular}{|c|c|c|}
\hline & ICD-9-CM Codes ${ }^{a}$ & Equivalent ICD-10-CM Codes ${ }^{a}$ \\
\hline \multicolumn{3}{|l|}{ For exclusion from study } \\
\hline Gestational diabetes & $648.8 \mathrm{x}$ & O99.81x \\
\hline Pregnancy-related claims & V22.x- V24.x, V27.x, 630.xx-679.xx & $\begin{array}{l}\text { Z33.x, Z34.xx, Z37.xx, Z39.x, O09.xxx, O60. } \\
\text { xxxx-O77.x, O80, O82, O85-O92.xxx }\end{array}$ \\
\hline Type 1 diabetes & $250 . x 1,250 . x 3$ & E10.xxxx \\
\hline \multicolumn{3}{|l|}{ Comorbidities } \\
\hline Type 2 diabetes & $250 . x 0,250 . x 2$ & Ell.xxxx \\
\hline Anxiety & $300.0 x$ & F4l.x \\
\hline Depression & $296.2 x, 296.3 x, 311$ & F32.xx, F33.xx \\
\hline \multicolumn{3}{|l|}{ Severe mental illness } \\
\hline Bipolar disorder & $296.0 x, 296.4 x-296.7 x, 296.80,296.89$ & F30.1, F31.xx \\
\hline Psychotic disorders (organic) & 292.xx-294.xx & F19.xx, F05, F04 \\
\hline Psychotic disorders (nonorganic, nonaffective) & 295.xx, 297.xx, 298.xx & F20.xx, F22, F23, F28, F29, F33.3, F44.89 \\
\hline Hypertension & 401.xx-405.xx & I10-I.15x \\
\hline Hyperlipidemia & $272.0-272.4,272.8,272.9$ & E78.xx \\
\hline Metabolic syndrome & 277.7 & E88.81 \\
\hline Coronary heart disease & $\begin{array}{l}410 . x x-411 . x x, 412,413 . x-417 . x, 427 . x x, 429.2 \\
429.9\end{array}$ & I20.xx-I25.xxx, I50.xx \\
\hline Heart failure & $428 . \mathrm{xx}$ & I50.xx \\
\hline Diabetic retinopathy & $362.0 x$ & E11.31x-E11.35xx \\
\hline Diabetic neuropathy & 357.2 & E11.4x \\
\hline Cerebrovascular disease & 433.xl, 434.xl, 435.9, 436, 437.1, 437.9 & \\
\hline Peripheral artery disease & $440.2 x, 440.3 x, 440.4,440.8,440.9$ & $170.2 x x-170.9 x$ \\
\hline Diabetic nephropathy & $250.40,250.42$ & E11.2xx \\
\hline Chronic kidney disease & 403.xx, 404.xx, 585.1-585.5, 585.9 & \\
\hline Chronic kidney disease & 585.x, 403.xx, 404.xx & N18.x, I12.x, I13.xx \\
\hline End-stage kidney disease & 585.6 & N18.6 \\
\hline Hypoglycemia & $251.0-251.2$ & E11.64x \\
\hline Overweight & 278.02 & E66.3 \\
\hline Obesity & $278.00,278.01$ & E66.0x-E66.2, E66.8-E66.9 \\
\hline \multicolumn{3}{|l|}{ Diabetic counseling } \\
\hline Lifestyle and medication counseling & V65.3, V58.67, V53.91, Z79.84 & $\mathrm{Z71.3,} \mathrm{Z79.4}$ \\
\hline CPT codes & \multicolumn{2}{|c|}{ G0108, G0109, 98960-98962, 97802-97804, 99078, S9140, S9141, S9145, S9455, S9460, S9465, S9470 } \\
\hline \multicolumn{3}{|l|}{ For aDCSI calculation } \\
\hline Retinopathy & $\begin{array}{l}\text { 250.5x, 361.xx, 362.01, 362.1, 362.83, 362.53, } \\
362.81,362.82,362.02,369 . x x, 379.23\end{array}$ & $\begin{array}{l}\text { E08.3x, E09.3x, E11.3x, E13.3x, H35.0x, H35.35x, } \\
\text { H35.6x, H35.8x, H35.9, H33.x, H54.x, H43.1x }\end{array}$ \\
\hline Nephropathy & $\begin{array}{l}250.4,580,581,581.81,582,583,585,586, \\
593.9\end{array}$ & $\begin{array}{l}\text { E08.21, E08.22, E08.29, E09.21, E09.22, E09.29, } \\
\text { E11.21, E11.22, E11.29, E13.21, E13.22, E13.29, } \\
\text { N00.x, N03.x-N05.x, N18.1, N18.2-N18.6, N18.9, } \\
\text { N19 }\end{array}$ \\
\hline Neuropathy & $356.9,250.6,358.1,951.0,951.1,951.3,357.2$ & $\begin{array}{l}\text { E08.4x, E09.4x, E11.4x, E13.4x, G56.x, G57.x, } \\
\text { G60.9, G73.3, G90.09, G90.1, G90.8, G90.9, } \\
\text { G99.0, H49.x, 195.1, K31.84, K59.1, N31.9, } \\
\text { M14.6x, S04.x }\end{array}$ \\
\hline Cerebrovascular & $431,433,434-436$ & G45.x, I61.x, I63.x, I65.x, I66.x, I67.81 \\
\hline Cardiovascular & $\begin{array}{l}410-414,427.1,427.3-427.5,428,429.2,440 . x x \\
441\end{array}$ & I20.x-I25.x, I46.x-I50.x, I70.x, I71.x \\
\hline Peripheral vascular disease & $\begin{array}{l}040.0,250.7,442.3,443.81,443.9,444.22,785.4 \\
707.1,892.1\end{array}$ & $\begin{array}{l}\text { E08.51, E08.59, E08.621, E09.51, E09.59, } \\
\text { E09.621, E11.51, E11.59, E11.621, E13.51, E13.59, } \\
\text { E13.621, I72.4, I70.21, I73.89, I73.9, I74.3, S91.3x, } \\
\text { A48.0, L97.x }\end{array}$ \\
\hline Metabolic & $250.1-250.3$ & $\begin{array}{l}\text { E08.00, E08.10, E08.649, E09.00, E09.10, } \\
\text { E09.649, E11.00, E11.10, E11.649, E13.00, E13.10, } \\
\text { E13.649, E08.01, E08.11, E08.641, E09.01, } \\
\text { E09.11, E09.641, E11.01, E11.11, E11.641, E13.01, } \\
\text { E13.11, E13.641 }\end{array}$ \\
\hline
\end{tabular}




\section{Factors Associated with Diabetes-Related Clinical Inertia in a Managed Care Population and Its Effect on Hemoglobin A1c Goal Attainment: A Claims-Based Analysis}

\section{APPENDIX A List of ICD-9/10-CM and CPT Codes (continued)}

\section{ICD-9-CM Codes ${ }^{\mathrm{a}}$}

To assess for possible medication-related adverse events

\begin{tabular}{l|l|l}
\hline Hypoglycemia & $251.0,251.2$ & E11.64 \\
\hline Nausea & $787.0 \mathrm{x}$ & R11.xx \\
\hline Edema & 782 & R60.x \\
\hline Urinary tract infection & 599.0 & N39.0 \\
\hline
\end{tabular}

aUnless otherwise specified.

aDCSI = adapted Diabetes Complications Severity Index; CPT-4 = Current Procedural Terminology, 4th Edition; ICD-9-CM=International Classification of Diseases, Ninth Revision, Clinical Modification; ICD-10-CM=International Classification of Diseases, Tenth Revision, Clinical Modification

\section{APPENDIX B List of Generic Product Identifiers}

Generic Drug Name

Biguanide

Metformin

Biguanide/nutritional supplement combinations

Sulfonylureas (SU)

Glipizide

Glyburide

Glimipiride

Tolazamide

Tolbutamide

Sulfonylurea/metformin combinations

Glipizide/metformin

Glyburide/metformin

Thiazolidinediones (TZDs)

Pioglitazone

Rosiglitazone

TZD/metformin combinations

Pioglitazone/metformin

Rosiglitazone/metformin

TZD/SU combination

Pioglitazone/glimepiride

Glucagon-like peptide-1 receptor agonist

Albiglutide

Dulaglutide

Exenatide

Liraglutide

Sodium-glucose co-transporter-2 inhibitors (SGLT2)

Canagliflozin

Dapagliflozin

Empagliflozin

SGLT2/metformin combinations

Canagliflozin/metformin

Dapagliflozin/metformin

Empagliflozin/metformin

Dipeptidyl peptidase-IV inhibitors (DPP-IV)

Alogliptin

Linagliptin

Saxagliptin

Sitagliptin
Brand Drug Name

Fortamet, Glucophage, Glumetza, Riomet

Appformin Pak, Appformin-D Pak

Glucotrol, Glucotrol XL, Glipizide XL

Diabeta, Glynase

Amaryl

Tolinase

Metaglip

Glucovance

Actos

Avandia

Actoplus Met, Actoplus Met XR

Avandamet

Duetact

Tanzeum

Trulicity

Bydureon, Byetta

Victoza

Invokana

Farxiga

Jardiance

Invokamet

Xigduo XR

Synjardy

Nesina

Tradjenta

Onglyza

Januvia
Generic Product Identifier

$2725 \mathrm{xxxx}$

27250050

279990xx

2720xxxx

27200030

27200040

27200027

27200050

27200060

279970xx

2799700235

2799700240

276070xx

27607050

27607060

279980xx

279980024

279980026

279978xx

27997802

$2717 \mathrm{xxxx}$

27170010

27170015

27170020

27170050

2770xxxx

27700020

27700040

27700050

279960xx

279960022

279960023

279960024

2755xxxx

27550010

27550050

27550065

27550070

continued on next page 


\section{Factors Associated with Diabetes-Related Clinical Inertia in a Managed Care Population and Its Effect on Hemoglobin A1c Goal Attainment: A Claims-Based Analysis}

\section{APPENDIX B List of Generic Product Identifiers (continued)}

\begin{tabular}{|c|c|c|}
\hline Generic Drug Name & Brand Drug Name & Generic Product Identifier \\
\hline \multicolumn{2}{|l|}{ DPP-IV/metformin combinations } & $279925 x x$ \\
\hline Alogliptin/metformin & Kazano & 27992502021 \\
\hline Sitagliptin/metformin & Janumet & 27992502024 \\
\hline Linagliptin/metformin & Jentadueto & 27992502026 \\
\hline Saxagliptin/metformin & Kombiglyze XR & 27992502027 \\
\hline \multicolumn{2}{|c|}{ DPP-IV/HMG CoA reductase combination } & $279930 x x$ \\
\hline Sitagliptin/simvastatin & Juvisync & $279930 x x$ \\
\hline \multicolumn{2}{|l|}{ DPP-IV/TZD combination } & $279940 x x$ \\
\hline Alogliptin/pioglitazone & Oseni & 27994002 \\
\hline \multicolumn{2}{|l|}{ DPP-IV/SGLT2 combination } & $279965 x x$ \\
\hline Empagliflozin/linagliptin & Glyxambi & 27996505 \\
\hline \multicolumn{2}{|l|}{ Alpha-glucosidase inhibitors } & $2750 \times x \times x$ \\
\hline Miglitol & Glyset & 27500050 \\
\hline Acarbose & Precose & 27500010 \\
\hline \multicolumn{2}{|l|}{ Meglitinides } & $2728 \times x \times x$ \\
\hline Nateglinide & Starlix & 27280040 \\
\hline Repaglinide & Prandin & 27280060 \\
\hline \multicolumn{2}{|l|}{ Meglitinide/metformin combination } & $279950 x x$ \\
\hline Repaglinide/metformin & Prandimet & $279950 x x$ \\
\hline \multicolumn{2}{|l|}{ Amylin mimetics } & $2715 \times x \times x$ \\
\hline Pramlintide & Symlin & $2715 \mathrm{xxxx}$ \\
\hline \multicolumn{2}{|l|}{ Insulins } & $271040 x x$ \\
\hline Insulin lispro & Humalog & 27104005 \\
\hline Insulin aspart & Novolog & 27104002 \\
\hline Insulin glulisine & Apidra & 27104004 \\
\hline Insulin aspart protamine/aspart & Novolog Mix 70/30 & 27104070 \\
\hline Insulin lispro protamine/lispro & Humalog Mix 50/50, Humalog Mix 75/25 & 27104080 \\
\hline Insulin NPH & Humulin N, Novolin N, Novolin ReliOn N & 27104020 \\
\hline Insulin regular & Humulin R U-500, Humulin R, Novolin R, Relion R, Afrezza & 27104010 \\
\hline Insulin NPH/regular & Humulin 70/30, Novolin 70/30 & 27104090 \\
\hline Insulin degludec & Tresiba & 27104007 \\
\hline Insulin glargine & Lantus, Toujeo & 27104003 \\
\hline Insulin detemir & Levemir & 27104006 \\
\hline
\end{tabular}

